\title{
The relevance of seed size in modulating leaf physiology and early plant performance in two tree species
}

\author{
Jesús Rodríguez-Calcerrada • Nikos Nanos • \\ Ismael Aranda
}

\begin{abstract}
The size of seeds and the microsite of seed dispersal may affect the early establishment of seedlings through different physiological processes. Here, we examined the effects of seed size and light availability on seedling growth and survival, and whether such effects were mediated by water use efficiency. Acorns of Quercus petraea and the more drought-tolerant Quercus pyrenaica were sowed within and around a tree canopy gap in a subMediterranean forest stand. We monitored seedling emergence and measured predawn leaf water potential $\left(\Psi_{\mathrm{pd}}\right)$, leaf nitrogen per unit area $\left(\mathrm{N}_{\mathrm{a}}\right)$, leaf mass per area, leaf carbon isotope composition $\left(\delta^{13} \mathrm{C}\right)$ and plant growth at the end of the first summer. Survival was measured on the next year. Path analysis revealed a consistent pattern in both species of higher $\delta^{13} \mathrm{C}$ as $\Psi_{\mathrm{pd}}$ decreased and higher $\delta^{13} \mathrm{C}$ as seedlings emerged later in the season, indicating an increase in ${ }^{13} \mathrm{C}$ as the growing season is shorter and drier.
\end{abstract}

J. Rodríguez-Calcerrada $(\bowtie)$

Centre of Functional and Evolutionary Ecology, CNRS,

1919 Route de Mende, 34293 Montpellier Cedex 5, France

e-mail: jesus.rodriguez-calcerrada@ cefe.cnrs.fr;

jesusrc1@yahoo.es

N. Nanos

School of Forest Engineering, Technical University of Madrid,

Ciudad Universitaria s/n, 28040 Madrid, Spain

I. Aranda

CIFOR, National Institute for Agricultural and Food Scientific Research and Technology (INIA), Carretera de La Coruña, Km. 7.5, 28040 Madrid, Spain
There was a direct positive effect of seed size on $\delta^{13} \mathrm{C}$ in Q. petraea that was absent in Q. pyrenaica. Leaf $\delta^{13} \mathrm{C}$ had no effect on growth but the probability of surviving until the second year was higher for those seedlings of $Q$. pyrenaica that had lower $\delta^{13} \mathrm{C}$ on the first year. In conclusion, leaf $\delta^{13} \mathrm{C}$ is affected by seed size, seedling emergence time and the availability of light and water, however, leaf $\delta^{13} \mathrm{C}$ is irrelevant for first year growth, which is directly dependent on the amount of seed reserves.

Keywords Phenology - Water stress - Recruitment . Seedling survival $\cdot{ }^{13} \mathrm{C}$

\section{Introduction}

The size of seeds and the microsite of seed dispersal are major determinants of the early establishment of seedlings of woody species. On one hand, seed size has generally a favourable effect on seedling survival and growth (Bonfil 1998; Castro et al. 2008; Quero et al. 2007) that may persist for various years (Seiwa 2000; Tripathi and Khan 1990). On the other hand, microsites of high overstory canopy closure provide poor conditions for numerous tree species, and seedlings tend to recruit in gaps or areas of sparse canopy cover (Asbjornsen et al. 2004; Gómez-Aparicio et al. 2008; Rodríguez-Calcerrada et al. 2010). It is yet unclear what physiological traits mediate the advantage of big seeds and gap plants, despite seed size and canopy closure may affect diverse aspects of plant physiology intimately linked to fitness (see Geber and Griffen 2003; Kennedy et al. 2004, and references therein).

Water reaches critically low values for plants in seasonally dry and arid ecosystems. Thus, maximizing net carbon assimilation relative to water loss, i.e. leaf water use 
efficiency (WUE), generally increases plant growth (Dudley 1996; Geber and Griffen 2003; Picotte et al. 2007) and survival (Casper et al. 2005; Ehleringer 1993) in these ecosystems. There are multiple ways in which seed size and dispersal microsite can affect leaf WUE. Since seed reserves provide a large part of first-year seedling' nitrogen (Villar-Salvador et al. 2010), a positive effect of seed size on leaf WUE is expected if seedlings from bigger seeds (i.e. with more reserves) have leaves with more nitrogen (Brookes et al. 1980; Tripathi and Khan 1990), higher nitrogen concentration (Khurana and Singh 2004), and thus higher carboxylation capacity relative to stomatal conductance to water vapour (Cordell et al. 1999). On the other hand, the microsite of seed dispersal affects leaf WUE in relation to the abundance of resources, such as water and light (Ehleringer and Cooper 1988). Under mild to moderate soil water deficit there is minor metabolic inhibition of net $\mathrm{CO}_{2}$ assimilation and stomatal regulation of water loss often leads to an increment of leaf WUE (Aranda et al. 2007; Flexas and Medrano 2002). Light, on the other hand, favours WUE partly by increasing the number of mesophyll layers on the leaves, which in turn, increases the amount of nitrogen per unit area and their photosynthetic capacity relative to the diffusion rate of $\mathrm{CO}_{2}$ into the chloroplasts (Aranda et al. 2007; Ponton et al. 2002).

Emergence time is an important component of fitness (Castro 2006; Seiwa 2000; Urbieta et al. 2008; Verdú and Traveset 2005) that is partly related to seed size (Du and Huang 2008; Tripathi and Khan 1990) and canopy closure (Augspurger et al. 2005; Jones et al. 1997; Seiwa 1998). Early emergence gives plants a performance advantage during recruitment due in part to the pre-emption of aboveand below-ground resources to competitors (Geber and Griffen 2003). Also, in Mediterranean-type climate habitats, early emergence allows for a larger time span for development before the onset of summer drought. A nonconservative water use can be expected in early emerging plants, given the high soil moisture and interspecific competition existing at the beginning of the growing season. The relationship between emergence time and leaf WUE remains unexplored in Mediterranean-type habitats despite seasonality in soil moisture and air evaporative demand is likely to affect physiological traits involved in carbon gain and water use. It is also ignored to what extent a potential effect of emergence time on leaf physiology reflects an indirect influence of other factors, such as seed size.

Path analysis is a good tool to untangle the complex relationships that underlie ecophysiological processes (e.g. Milla et al. 2009; Picotte et al. 2007). In this study, we use path analysis to explore the effects of seed size and light availability on the growth of 1-year-old seedlings of Quercus pyrenaica Willd and Quercus petraea (Matt.)
Liebl. in a sub-Mediterranean forest stand. Previous studies have pointed out that seedlings of the temperate $Q$. petraea are more competitive in resource-high conditions and seedlings of the sub-Mediterranean Q. pyrenaica are more resistant to (competitive in) resource-poor conditions (Rodríguez-Calcerrada et al. 2008, 2010). The more competitive character of $Q$. petraea is reflected in a higher responsiveness of shoot growth to light and could also involve a higher allocation of seed reserves to shoots (Long and Jones 1996; Rodríguez-Calcerrada et al. 2008, 2010). Such rapid vertical growth (relative to $Q$. pyrenaica), however, may compromise its survival in sub-Mediterranean populations, where summer drought is recurrent and critical for seedlings. Here, we hypothesized the existence of an indirect effect of seed size and light availability on plant growth through their effects on emergence time and leaf WUE. We expected that $Q$. petraea and $Q$. pyrenaica presented similar functional relationships among traits due to common effects of light and water deficit on leaf physiology and plant growth and a conserved influence of seed size on these traits in the first year of germination; nonetheless, we expected that the magnitude of some relationships would change according to their contrasting ecology. More specifically, we expected a stronger effect of seed size than light on first-year growth, and that seed size and light would be more relevant for growth of $Q$. petraea than for the slower growing $Q$. pyrenaica. Since the maternal origin is a significant source of variation in traits affecting early plant performance, such as seed size, plant growth (Castro et al. 2008) and leaf WUE (Sandquist and Ehleringer 2003), we included the identity of the mother tree as a factor in general linear mixed-effects models (GLMMs) to test for potential maternal effects on the relationships between traits. Finally, we measured seedling survival in the second year, under the expectation that the probability of survival would be higher for those seedlings exhibiting high leaf WUE.

\section{Methods}

Study site

The study site is located in the "El Hayedo de Montejo" forest, in the northeast of Madrid province (Spain $41^{\circ} 07^{\prime} \mathrm{N}$, $3^{\circ} 30^{\prime} \mathrm{W}$ ). This forest has been intensively managed for firewood production and livestock grazing until the first half of the twentieth century, when the ceasing of activities led to the infilling of the ancient open woodland. Today, it is formed by pure to mixed stands of $Q$. pyrenaica, Q. petraea, Fagus sylvatica and Ilex aquifolium, with $Q$. petraea and F. sylvatica being close to their southernmost edge of distribution (see Nanos et al. 2005 for more 
details). The climate is sub-Mediterranean, with $958 \mathrm{~mm}$ annual rainfall and only $159 \mathrm{~mm}$ from June to September. Mean annual temperature is $9.5^{\circ} \mathrm{C}$ and the mean from June to September is $16.8^{\circ} \mathrm{C}$ (average data for a 14-year period in the study site). The soil is fertile and well drained, originated from a micaceous gneiss rock bed.

\section{Study plot and design}

The study was conducted in an $11 \times 15 \mathrm{~m}$ plot; gently sloping $(12.6 \%)$, oriented to the SE $\left(140.7^{\circ}\right)$ and dominated by $Q$. pyrenaica in the overstory (of about $12 \mathrm{~m}$ canopy height). Elevation is $1,415 \mathrm{~m}$ asl and mean topsoil bulk density is $0.75 \mathrm{~g} \mathrm{~cm}^{-3}$. The plot has a $50 \mathrm{~m}^{2}$ canopy gap in the mid-bottom part. This gap was not caused by the recent fall of any tree; rather, the presence of several trees of Crataegus monogyna in the north border suggests an old colonization by light-demanding woody species. Across the site there were only few sparse shrubs of Rosa micrantha and Rubus sp. Cover of herbaceous plants was high (mean $45 \%$ in spring). Herbs Asphodelus albus, Torilis japonica and Galium aparine and grasses Melica uniflora and Poa nemoralis were the most abundant species.

In autumn 2007, an indeterminate number of acorns were collected from three maternal trees of $Q$. petrae $a$ and four of $Q$. pyrenaica. In the laboratory, we measured the length and width of all viable acorns and painted them with different colours to identify the species and maternal tree. A total of 1,120 acorns were then put into galvanized wire cages $(10 \mathrm{~mm}$ mesh size) to prevent predation by rodents in the field. Acorns were separated about $8 \mathrm{~cm}$ within the cages. Sowing took place in November 2007. Cages were buried approximately at $2 \mathrm{~cm}$ depth (with litter replaced on top after burial) across 160 points systematically distributed in the plot. Cages had three (occasionally two) acorns of $Q$. petraea and four (occasionally five) acorns of $Q$. pyrenaica, with at least one acorn per maternal tree. The position of each acorn was annotated at sowing. The controlled sowing allowed for an even distribution of acorns across microsites while avoiding bias in seed size or seedling density. The plot was fenced for excluding domestic cattle to browse the plants.

\section{Plant measurements}

Measurements were made on seedlings from three maternal trees of $Q$. petraea and $Q$. pyrenaica. We followed emergence regularly since April 2008. The day of seedling emergence (DOE) was computed as the first day the epicotyl was observed. At the end of summer (early September), we selected 74 plants from $Q$. petraea and 71 from $Q$. pyrenaica that had emerged in different dates and were widely distributed around and within the gap for measurements of growth (height, stem-diameter, and total leaf area), leaf mass per area (LMA), leaf predawn water potential $\left(\Psi_{\mathrm{pd}}\right)$, leaf nitrogen concentration $\left(\mathrm{N}_{\mathrm{m}}\right)$, and leaf carbon isotope composition $\left(\delta^{13} \mathrm{C}\right)$. In general, we sampled one seedling of each species in the same burial site. Height was measured with a ruler to the nearest $0.1 \mathrm{~cm}$ and stem diameter with a digital calliper to the nearest $0.01 \mathrm{~mm}$. Total leaf area was calculated as the sum of the area of all individual leaves. Then leaves were oven-dried for 3 days at $60^{\circ} \mathrm{C}$ and powdered for analyses of $\mathrm{N}_{\mathrm{m}}$ and $\delta^{13} \mathrm{C} . \mathrm{N}_{\mathrm{m}}$ was determined with the Kjeldahl method. The content of nitrogen per unit of leaf area $\left(\mathrm{N}_{\mathrm{a}}\right)$ was estimated by multiplying $\mathrm{N}_{\mathrm{m}}$ and LMA. Leaf carbon isotope composition $\left(\delta^{13} \mathrm{C}\right)$ was determined with an elemental analyzer (Carlo Erba 1108) coupled to a mass spectrometer IRMS (Isochrom, Micromass), with a precision of $\pm 0.2 \%$. Leaf $\delta^{13} \mathrm{C}$ is widely used as a long-term indicator of WUE (e.g. Ehleringer 1993; Farquhar et al. 1982, 1989). Predawn water potential $\left(\Psi_{\mathrm{pd}}\right)$ was measured in one leaf per plant with a pressure chamber (PMS Instrument Company, Albany, USA) to the nearest $0.025 \mathrm{MPa}$. Finally, in September 2009, we examined whether the seedlings that had been sampled in 2008 were alive or dead.

In addition, we monitored canopy closure by assigning the development of buds and leaves of overstory trees (six branches per tree) to several phenological categories going from bud break to full leaf expansion.

\section{Microenvironment measurements}

We assumed homogeneous environmental conditions for the seven seeds buried per site $(30 \times 20 \mathrm{~cm}$ size $)$, so we measured light and soil water content in one point per burial site. Understory light availability was measured by means of hemispherical photography and volumetric soil water availability by means of time domain reflectometry (TDR). The hemispherical photographs were made at $50 \mathrm{~cm}$ height with a digital camera (Nikon Coolpix 995, Tokyo, Japan) coupled to an $8 \mathrm{~mm}$ fisheye lens and mounted on a self-levelling base. They were made on overcast conditions within 1 week at the end of August, when tree canopy cover was complete. Since no defoliation or branch fall occurred over the growing season, this measure reflects the light availability of the whole period whereby canopy closure was complete. We used the software Hemiview (Delta T Devices Ltd., Cambridge, UK) to analyze the images and calculate the proportions of direct and diffuse radiation relative to those above the canopy. We used the global site factor index (GSF, calculated from values of direct and diffuse radiation, and ranging from 0 to $100 \%$ ) to estimate light availability (Rich 1990). Volumetric topsoil moisture was measured every $10-15$ days 
since the 15th of April using a Trime-FM3 mobile meter coupled to probes $16 \mathrm{~cm}$ deep (IMKO Micromodultechnik $\mathrm{GmbH}$, Ettlingen, Germany). All measurements were taken not further than $10 \mathrm{~cm}$ from the burial site and were performed at different points between dates.

\section{Data analysis}

Some plants emerging very late in summer were excluded from the analyses. The final number of observations was 70 per species $(18,34$ and 18 per family for $Q$. pyrenaica, and 29,14 and 27 for Q. petraea). We used statistical packages Statistica 7.1 (Stat Soft Inc., OK, USA), AMOS 5.0 (AMOS development Corp., SC, USA) and R (R development Core Team 2009) for analyses.

We compared the two species and the three families per species using ANCOVA's, with species as the main factor, family nested within species, and seed size (see below) as a covariate. Separate analyses were made for response variables $\Psi_{\mathrm{pd}}$, LMA, $\mathrm{N}_{\mathrm{a}}$, plant growth (see below), and $\delta^{13} \mathrm{C}$. $\Psi_{\text {pd }}$ had positive skew and kurtosis and was transformed as: $-\log$ (square root $\left[-\Psi_{\mathrm{pd}}\right]$ ). Highly correlated variables height, stem-diameter and total leaf area were reduced into a new variable (plant vertical growth; hereafter plant growth) by means of principal component analysis (PCA). Seed width and length were similarly combined into a "seed size" variable by PCA.

We explored the relationships between all variables and saw that these were absent or linear (Electronic supplementary Figs. 1 and 2). Thereafter, we studied the relationships among seed size, light availability, leaf physiology and growth with path analysis. Based on a general conceptual model (Fig. 1), several specific alternate models were produced with the variables in our data set, and the one with the strongest empirical support was finally selected. We tested for the significance of any difference in the model between $Q$. pyrenaica and $Q$. petraea though multigroup analysis (Arbuckle 2003; Shipley 2000). First, we examined whether the same causal structure applied to both species. Then, we examined whether any path coefficient differed significantly between the species. If a constrained model (with all coefficients imposed to be equal between species) had a low probability level $(P<0.05)$, we rejected the hypothesis of total equality of path coefficients and examined which coefficients differed between the species by releasing one between-species equality constraint at a time (Arbuckle 2003; Shipley 2000). Given a slight departure from multivariate kurtosis, the function used to fit the models was the generalized least squares function instead of the maximum likelihood function. The degree of model fit to the data was evaluated with (1) the $\chi^{2}$ test-with associated $P$ values $>0.05$ indicating an acceptable fit at a $5 \%$ significance level-and (2) the goodness-of-fit (GFI) testwith GFI $>0.90$ indicating an acceptable fit. Only one variable indicative of plant water availability was included in the model; we preferred $\Psi_{\mathrm{pd}}$ to soil moisture because the tap root of seedlings can go much deeper than the $16 \mathrm{~cm}$ sampled with the TDR. Since understory light availability was not measured before seedlings emerged, we did not specify a link between variables light availability and seedling emergence day in the path models.

The effect of acorn- and/or seedling-specific covariates on those traits found to differ significantly among families (i.e. plant growth and leaf $\delta^{13} \mathrm{C}$; see "Results") was studied with the use of GLMMs. This model does not assume independence among observations of the same group (i.e. acorns of the same family) and allows for the randomeffect estimation of family (nested within species). Initially, we introduced as fixed effects the full spectrum of explanatory variables, including environmental variables. Confidence intervals and $P$ values for the fixed effects of the model were assessed via Markov Chain Monte Carlo (MCMC) according to the procedure described in Baayen
Fig. 1 Proposed hypothetical framework to describe the effects of seed size and light availability on plant growth via leaf WUE (see "Introduction")

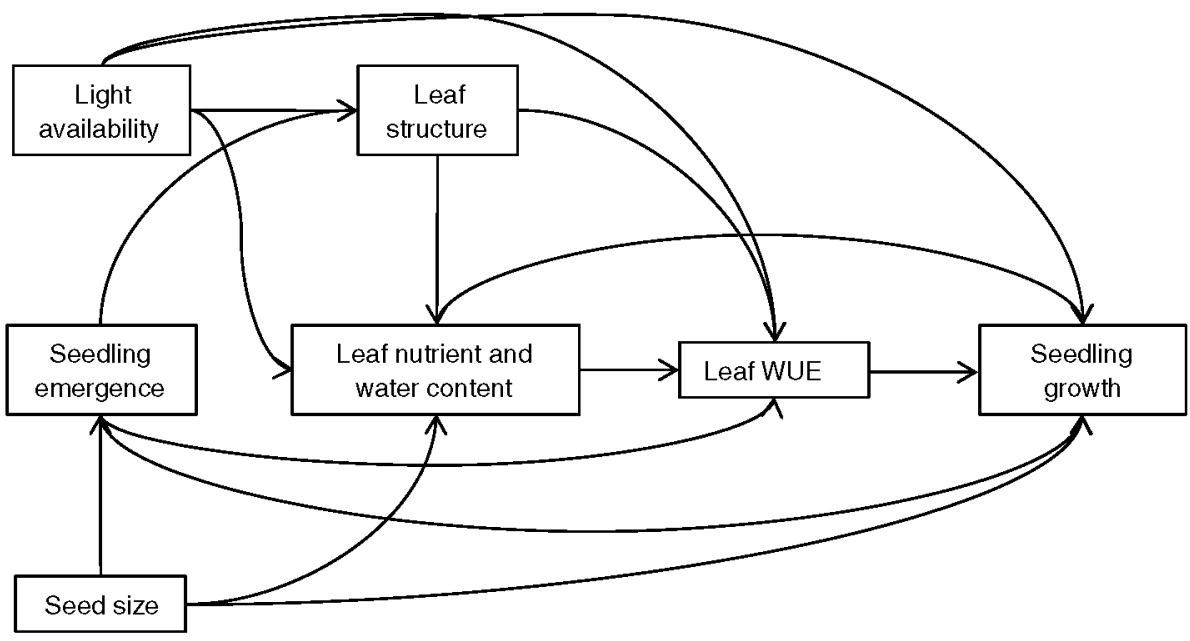


et al. (2008) - instead of using a classical approach due to the difficulties in estimating the degrees of freedom of parameters in GLMM. Fixed effects estimates that were found to be not significant after MCMC were removedone at a time-from the model. Likelihood ratio tests were also used to assess the significance of dropping fixed effects from the "full" model. Model parameters were estimated via restricted maximum likelihood using the "Ime4" R-library (Bates 2005).

Finally, we examined the relationship between the probability of seedling survival in the second growing season and the variables measured during the first year. We used separate logistic regression models for each variable, specifying a binomial error distribution for survival (1: alive, 0: dead) and logit link functions. Sampling for physiology inevitably involved defoliation of plants, and it is possible that any impacts were dependent on the size of seeds and seedlings. For this reason, seed size and plant growth variables were not included into this analysis.

\section{Results}

Climatic conditions

Rainfall was abundant in spring $(392 \mathrm{~mm}$, for a total of $892 \mathrm{~mm}$ recorded in 2008) but low in summer ( $83 \mathrm{~mm}$, with $4 \mathrm{~mm}$ in August). Air vapour pressure deficit increased from spring through summer (with mean daily values in the understory being $0.27,0.72$ and $1.17 \mathrm{kPa}$ on May, June and August, respectively), whereas soil moisture decreased progressively from spring through summer. The maximum value of soil moisture (37\%) was recorded on 19 May, with values declining to $28 \%$ by the end of June and down to $9 \%$ by the end of August. That is, as seedlings emerged later in the season they were exposed to drier air and soil conditions, as typically occurs in Mediterranean forests.

\section{Species traits}

First seedlings appeared by the beginning of May. Emergence peaked on 19 May for Q. petraea and on 3 June for $Q$. pyrenaica and it continued well into the summer (Fig. 2). Approximately $77 \%$ of seedlings of $Q$. pyrenaica emerged before leaves of overstory trees were fully expanded and the proportion increased to $96 \%$ in the case of $Q$. petraea. At the end of summer only two seedlings had produced two shoot flushes. By this time, seedlings of Q. petraea had lower $\Psi_{\mathrm{pd}}$, higher growth, and higher leaf $\delta^{13} \mathrm{C}$ than those of $Q$. pyrenaica (Fig. 3). When seed size (higher in $Q$. petraea than $Q$. pyrenaica) was analysed as a covariate in ANCOVA, $\Psi_{\mathrm{pd}}$ and leaf $\delta^{13} \mathrm{C}$ were significantly different between the species at $P<0.01$ and plant

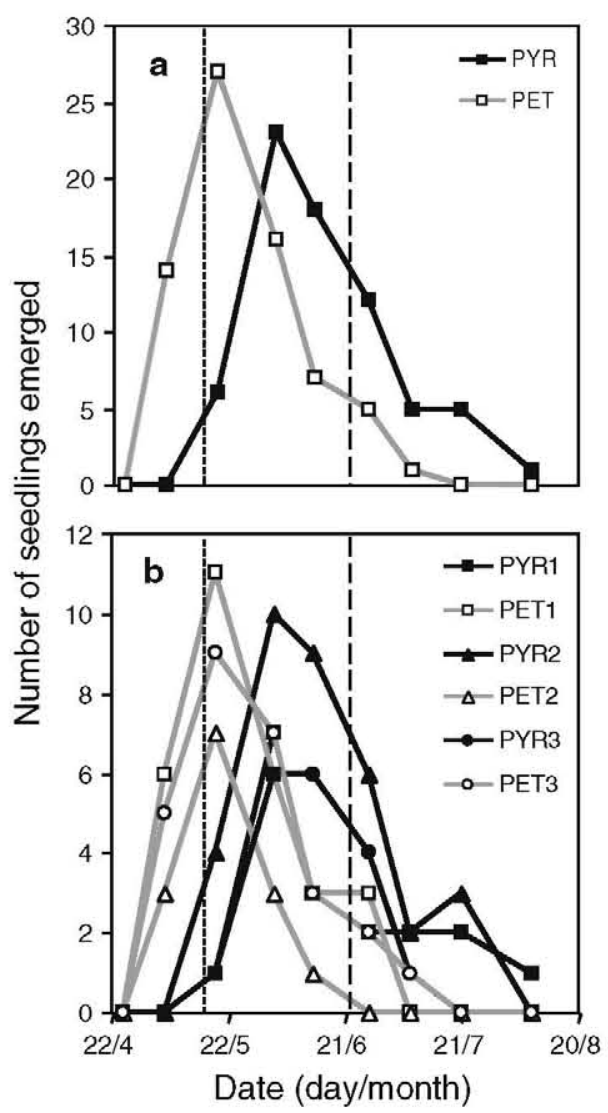

Fig. 2 Seedling emergence date by a species [Quercus pyrenaica (PYR) and Quercus petraea (PET)] and b family (PYR 1-3 and PET 1-3). Dotted and dashed lines mark dates of bud break and leaf full expansion of overstory trees, respectively

growth was marginally significantly different (Table 1 ). Intraspecific variability was high. We note the consistent divergence of family PET3 with respect to the other two $Q$. petraea families. PET3 seedlings had the largest seeds and showed the highest growth and leaf $\delta^{13} \mathrm{C}$ at the end of summer. No significant family effect was seen for variables LMA, $\mathrm{N}_{\mathrm{a}}$ and emergence time (Table 1). Light availability (ranging across microsites from 2.2 to $22.7 \%$ ) and soil moisture (ranging across microsites from 27 to $49 \%$ in spring and 4 to $22 \%$ at the end of summer) did not differ between species or families $(P>0.10$; data not shown).

\section{Causal relationships among traits}

The most plausible model representing the causal relationships among variables in our data set did not include any effect of seed size on seedling emergence time; neither light availability (GSF) or seed size were relevant for water availability $\left(\Psi_{\mathrm{pd}}\right)$ or leaf nitrogen content (Fig. 4). In contrast, $\Psi_{\mathrm{pd}}$ had a consistent negative direct effect on leaf $\delta^{13} \mathrm{C}$. Also, GSF affected $\delta^{13} \mathrm{C}$, directly in $Q$. petraea and indirectly [through a LMA-mediated positive effect on 
Fig. 3 Mean values $( \pm$ SE) of a seed size, b plant growth, c leaf predawn water potential $\left(\Psi_{\mathrm{pd}}\right), \mathbf{d}$ leaf carbon isotope composition $\left(\delta^{13} \mathrm{C}\right)$, e leaf mass per area $(L M A)$, and $\mathbf{f}$ nitrogen per unit area $\left(\mathrm{N}_{\mathrm{a}}\right)$ for three families of Quercus pyrenaica (filled bars) and Quercus petraea (open bars). Units for seed size and plant growth are axis-I scores from principal component analyses including variables seed length and width (for seed size) and height, stem diameter and total leaf area (for plant growth). For comparison, seed length was $2.46,2.44$ and $2.33 \mathrm{~cm}$ for $Q$. pyrenaica families $1-3$, and $2.90,2.59$ and 3.36 for $Q$. petraea families $1-3$, respectively; seedling diameter was 2.02, 2.14 and $2.00 \mathrm{~mm}$ for $Q$. pyrenaica families $1-3$, and 2.71, 2.67 and $3.36 \mathrm{~mm}$ for $Q$. petraea families $1-3$, respectively
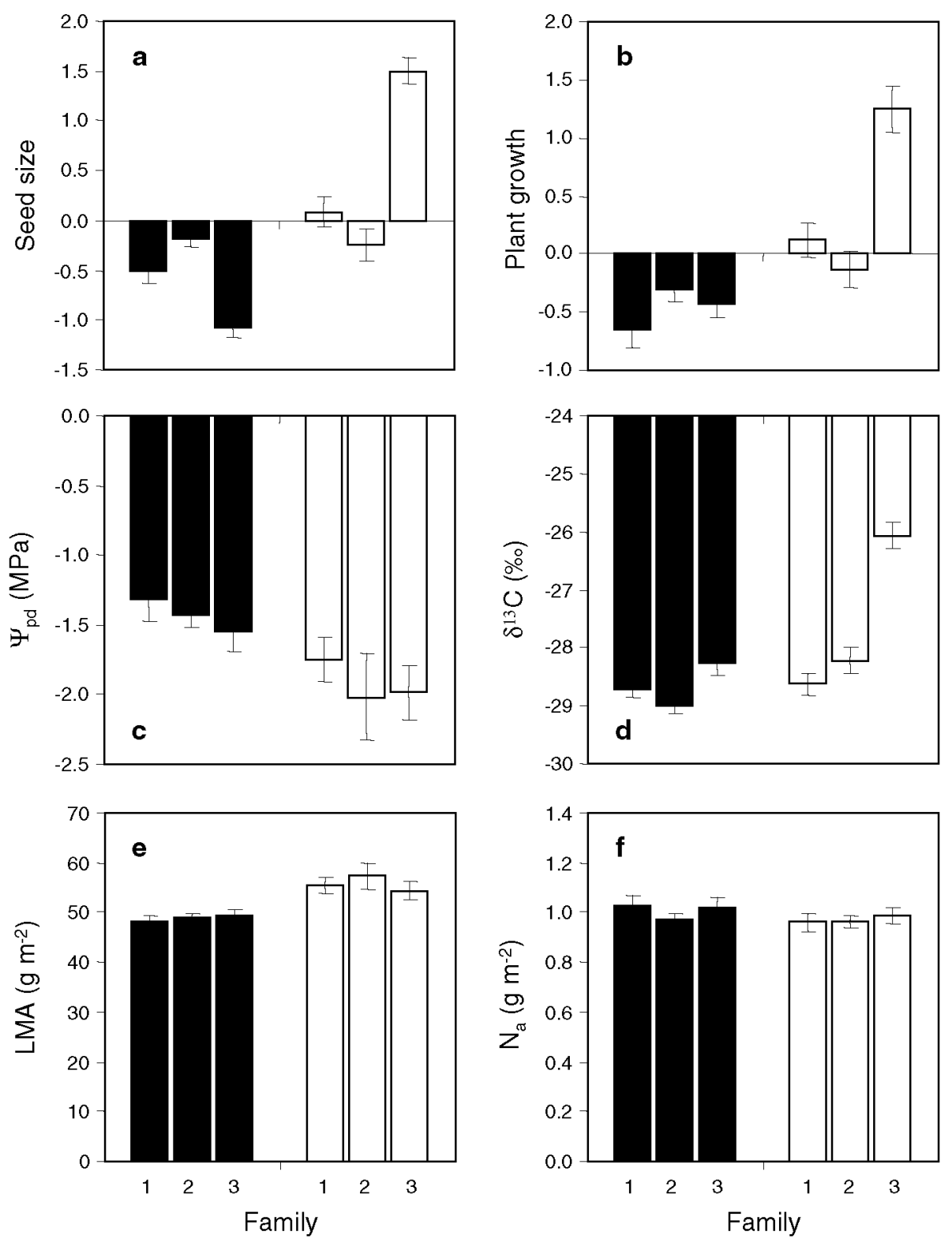

nitrogen content per unit area $\left.\left(\mathrm{N}_{\mathrm{a}}\right)\right]$ in $Q$. pyrenaica (Fig. 4). The standardized coefficients for the total effect of light on leaf $\delta^{13} \mathrm{C}$ (i.e. after accounting for direct and indirect effects) were 0.26 and 0.21 for $Q$. petraea and $Q$. pyrenaica, respectively. Seedling emergence time had a consistent positive direct effect on leaf $\delta^{13} \mathrm{C}$. In turn, leaf $\delta^{13} \mathrm{C}$ had no effect on plant growth on any species.

The structure of this model fitted adequately to the data of both species $\left(\chi^{2}=28.608, d f=24, P=0.235\right)$ so we proceeded testing for total equality of path coefficients assuming a common structure in the models. Constraining the path coefficients to be equal for both species rendered a model that was erroneous at a $5 \%$ significance level $\left(\chi^{2}=52.836, d f=34, P=0.021\right)$. Releasing the constraint that both species had equal regression coefficients for the path linking seed size and leaf $\delta^{13} \mathrm{C}$ improved significantly the model at a Bonferroni-corrected $0.5 \%$ significance level (change in $\chi^{2}=12.382, \quad d f=1$, $P=0.000$ ). Indeed, seed size had a positive direct effect on $\delta^{13} \mathrm{C}$ for $Q$. petraea but no similar effect was detected for Q. pyrenaica (Fig. 4). Differences in magnitude concerning the removal of between-species equality constraints in the rest of paths were clearly not significant.

\section{Mixed effects modelling}

The number of observations was insufficient for testing our final causal model at the family level (Bentler 1989). Thus, we made GLMMs to take into account a potential maternal effect on the relationships involving those traits for which a significant maternal effect existed: plant growth and $\delta^{13} \mathrm{C}$. 
Table 1 Results of ANOVA testing for the effects of species and family (nested within species) on seed size, and of ANCOVAs testing for the effects of species, family and seed size on plant growth, leaf mass per area (LMA), nitrogen per unit area $\left(\mathrm{N}_{\mathrm{a}}\right)$, leaf predawn water potential $\left(\Psi_{\mathrm{pd}}\right)$, and leaf carbon isotope composition $\left(\delta^{13} \mathrm{C}\right)$

\begin{tabular}{|c|c|c|c|c|c|}
\hline Variable & SS & $d f$ & MS & $F$ & $P$ \\
\hline \multicolumn{6}{|l|}{ Seed size } \\
\hline $\mathrm{Sp}$ & 34.22 & 1 & 34.22 & 90.46 & 0.000 \\
\hline Fam (Sp) & 48.91 & 4 & 12.23 & 32.32 & 0.000 \\
\hline Error & 50.69 & 134 & 0.38 & & \\
\hline \multicolumn{6}{|l|}{ Plant growth } \\
\hline Sp & 1.61 & 1 & 1.60 & 3.77 & 0.054 \\
\hline Fam (Sp) & 4.79 & 4 & 1.20 & 2.82 & 0.028 \\
\hline Seed size & 16.07 & 1 & 16.07 & 37.77 & 0.000 \\
\hline Error & 56.58 & 133 & 0.42 & & \\
\hline \multicolumn{6}{|l|}{ LMA } \\
\hline $\mathrm{Sp}$ & 710.59 & 1 & 710.59 & 13.35 & 0.000 \\
\hline Fam (Sp) & 116.82 & 4 & 29.20 & 0.55 & 0.700 \\
\hline Seed size & 23.39 & 1 & 23.39 & 0.44 & 0.508 \\
\hline Error & 7076.46 & 133 & 53.21 & & \\
\hline \multicolumn{6}{|l|}{$N_{a}$} \\
\hline $\mathrm{Sp}$ & 0.08 & 1 & 0.08 & 3.06 & 0.083 \\
\hline Fam $(\mathrm{Sp})$ & 0.08 & 4 & 0.02 & 0.78 & 0.543 \\
\hline Seed size & 0.04 & 1 & 0.04 & 1.53 & 0.218 \\
\hline Error & 3.54 & 133 & 0.03 & & \\
\hline \multicolumn{6}{|l|}{$\Psi$ pd } \\
\hline $\mathrm{Sp}$ & 0.10 & 1 & 0.10 & 12.71 & 0.001 \\
\hline Fam $(\mathrm{Sp})$ & 0.03 & 4 & 0.01 & 1.02 & 0.398 \\
\hline Seed size & 0.01 & 1 & 0.01 & 1.25 & 0.265 \\
\hline Error & 1.07 & 133 & 0.01 & & \\
\hline \multicolumn{6}{|l|}{$\delta^{13} \mathrm{C}$} \\
\hline $\mathrm{Sp}$ & 10.03 & 1 & 10.03 & 11.32 & 0.001 \\
\hline Fam $(\mathrm{Sp})$ & 64.86 & 4 & 16.22 & 18.29 & 0.000 \\
\hline Seed size & 3.86 & 1 & 3.87 & 4.36 & 0.039 \\
\hline Error & 117.89 & 133 & 0.89 & & \\
\hline
\end{tabular}

Bold values are statistically significant $(P<0.05)$

Plant growth at the end of the first growing season was only significantly associated with the size of seeds and the date of seedling emergence (Table 2). The fixed effect of species was not significant within this model, as well as the environmental variables considered in this study and other seedling-specific covariates. The standard deviation of the random family effect was relatively small, something that can also be observed in Fig. 5 displaying the predicted family random effects along with their $95 \%$ predicted confidence interval (i.e. note that all the prediction intervals include zero).

Apart from seed size and seedling emergence date, $\delta^{13} \mathrm{C}$ was found to be associated with $\mathrm{N}_{\mathrm{a}}$ and $\Psi_{\text {pd }}$. In this case several family random effects (Fig. 5) did not include zero in their prediction interval in accordance to their estimated standard deviation (Table 2). Finally, although species membership was not found to be a significant fixed effect, families of $Q$. petraea seemed to have larger predicted random effect coefficients (Fig. 5).

\section{Second-year survival}

Seedling survival was measured at the end of the second growing season: $79 \%$ of $Q$. pyrenaica and $66 \%$ of $Q$. petraea seedlings survived (Wald test for species comparison $=2.84, P=0.092$ ). We analyzed the effect of measured variables on the survival of each species. Leaf $\delta^{13} \mathrm{C}$ had a significant effect on the probability of survival of $Q$. pyrenaica (Table 3), with surviving seedlings having lower $\delta^{13} \mathrm{C}$ during the first growing season. Contrastingly, the probability of survival of $Q$. petraea was affected exclusively by $\Psi_{\mathrm{pd}}$, with surviving seedlings having higher values of $\Psi_{\mathrm{pd}}$ than dying ones (Table 3).

\section{Discussion}

Controls of first-year vertical growth

First-year vertical growth of $Q$. petraea and $Q$. pyrenaica was governed by seed size. The benefits of seed size for growth were not mediated by a better access of seedlings to water or a higher concentration of leaf nitrogen. Rather, the direct link between seed size and plant growth found by path analysis suggests a translocation of seed carbohydrates to plant organs, in support of previous works that found that early seedling growth was strongly determined by seed cotyledonary reserves (Kennedy et al. 2004; Seiwa 2000; Urbieta et al. 2008). Since both species have an episodic flush-type pattern of shoot growth and most seedlings did not produce a second shoot flush after emergence, leaf WUE was irrelevant for plant growth, at least for vertical plant growth. It is important to note that we computed plant growth as the PCA scores resulting from variables height, diameter and total leaf area. We might have found different results if we had measured seedling mass, as it seems reasonable that biomass accumulation be more sensitive than vertical growth to detect any effect of physiological traits (Dudley 1996). Light availability was also irrelevant for growth because seedlings flushed once and mostly before overstory trees fully expanded their leaves. Understory light availability measured at the time when canopy closure was complete could have no effect on growth if seedlings achieved most of their annual growth before canopy closure. Phenological avoidance of overstory canopy closure has shown to be an important factor for growth of seedlings in deciduous hardwood forests (Augspurger 
Fig. 4 Path model of the effects of seed size and light availability on plant growth for Quercus pyrenaica and Quercus petraea. By each path, we show the standardized path coefficient and its significance ( ${ }^{\mathrm{ns}} P \geq 0.05$, ${ }^{*} P<0.05, * * P<0.01$, ${ }_{* * *} P<0.001$ ), with thick lines highlighting significant paths.

By each endogenous (response) variable, we show its unexplained proportion of residual variance. The proportion of variation in Plant growth explained by the model $\left(R^{2}\right)$, and the overall goodnessof-fit $\left(\chi^{2}, P\right.$ and GFI) and degrees of freedom $(d f)$ of the model are also shown.

Correlations among exogenous (predictor) variables were included in the model but are not shown for clarity. GSF, light availability; DOE, date of emergence; LMA, leaf mass per area; $\mathrm{N}_{\mathrm{a}}$, leaf nitrogen per unit area; $\left(\Psi_{\mathrm{pd}}\right)$, leaf predawn water potential; $\delta^{13} \mathrm{C}$, leaf carbon isotope composition
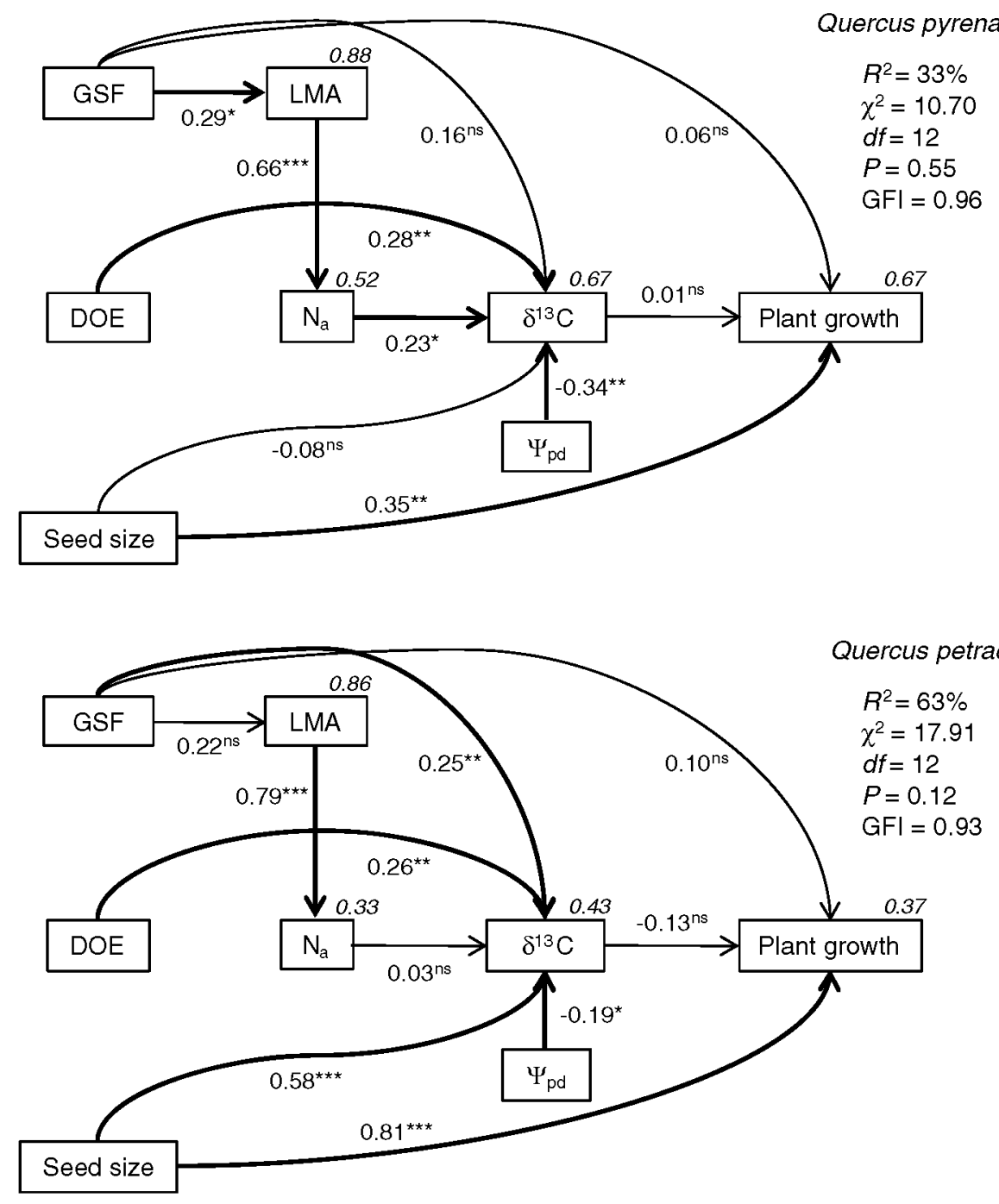

Table 2 Linear mixed-effects model for plant growth and leaf $\delta^{13} \mathrm{C}$

\begin{tabular}{|c|c|c|c|c|c|c|}
\hline Response variable & Parameter & Estimate & MCMC mean & 95\% Lower & 95\% Upper & $P$ value MCMC \\
\hline \multirow[t]{5}{*}{ Plant growth } & Intercept & 1.196 & 1.163 & 0.250 & 2.097 & 0.014 \\
\hline & Seed size & 0.550 & 0.538 & 0.386 & 0.676 & 0.000 \\
\hline & DOE & -0.007 & -0.007 & -0.013 & -0.001 & 0.011 \\
\hline & Family & 0.137 & & & & \\
\hline & Residual & 0.592 & & & & \\
\hline \multirow[t]{7}{*}{$\delta^{13} \mathrm{C}$} & Intercept & -32.659 & -32.572 & -34.322 & -30.836 & 0.0001 \\
\hline & Seed size & 0.351 & 0.394 & 0.161 & 0.639 & 0.0006 \\
\hline & DOE & 0.019 & 0.019 & 0.010 & 0.027 & 0.0002 \\
\hline & $N_{\mathrm{a}}$ & 0.964 & 0.949 & 0.062 & 1.902 & 0.0448 \\
\hline & $\Psi \mathrm{pd}$ & -0.284 & -0.296 & -0.489 & -0.119 & 0.0034 \\
\hline & Family & 0.879 & & & & \\
\hline & Residual & 0.845 & & & & \\
\hline
\end{tabular}

The parameter Family is the estimated standard deviation of the family random effect and Residual is the standard deviation of the residuals of the model

DOE, day of seedling emergence; $\mathrm{N}_{\mathrm{a}}$, nitrogen per unit area; $\Psi_{\mathrm{pd}}$, leaf predawn water potential 

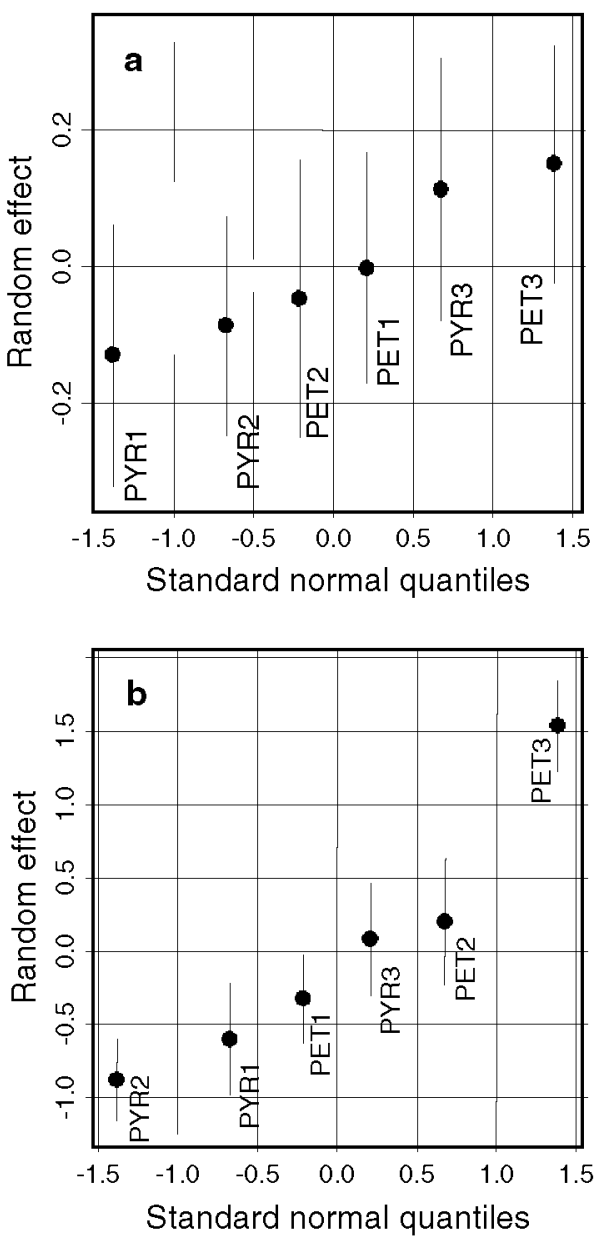

Fig. 5 Predicted family random effects and 95\% confidence intervals for $\mathbf{a}$ the plant growth model and $\mathbf{b}$ the leaf $\delta^{13} \mathrm{C}$ model

et al. 2005; Seiwa 1998). This may also explain the small but significant effect of emergence date on growth seen in the GLMM model (Table 2), with late-emerging seedlings growing less than early-emerging ones.

Seed size, plant growth and leaf $\delta^{13} \mathrm{C}$ showed a maternal effect (Table 1). This makes possible that the effects of seed size on plant growth and leaf $\delta^{13} \mathrm{C}$ observed at the species level (Fig. 4) be actually attributed to a common genetic or phenotypic effect of the mother tree on these variables and not to a true mechanistic relationship. All the predicted family random effects include zero in their prediction interval when the linear model relating plant growth to seed size is considered. On the contrary, this is not the case for some family random effects in the model relating leaf $\delta^{13} \mathrm{C}$ to seed size. Accordingly, it seems logical to conclude that the relationship between seed size and plant growth is a purely mechanistic one (see Castro et al. 2008), but that maternally inherited effects (not related to seed size) seem to exist in the relationship between seed size and leaf $\delta^{13} \mathrm{C}$.
Table 3 Mean values of several traits at the end of the first growing season in seedlings of Quercus pyrenaica (PYR) and Quercus petraea (PET) that either survived or died by the second year, with significance of differences after separate logistic regression analyses also shown

\begin{tabular}{llccll}
\hline Variable & Species & \multicolumn{2}{c}{ Mean values } & Wald test & $P$ value \\
\cline { 3 - 4 } & & Surviving & Dying & & \\
\hline GSF & PYR & 11.60 & 11.42 & 0.03 & 0.871 \\
& PET & 10.88 & 11.38 & 0.30 & 0.581 \\
DOE $^{\mathrm{a}}$ & PYR & 165 & 165 & 1.66 & 0.197 \\
& PET & 140 & 155 & 0.08 & 0.774 \\
LMA & PYR & 48.61 & 49.67 & 0.49 & 0.484 \\
& PET & 54.80 & 56.35 & 0.50 & 0.479 \\
$\mathrm{~N}_{\mathrm{a}}$ & PYR & 0.98 & 1.06 & 2.81 & 0.094 \\
& PET & 0.99 & 0.92 & 2.84 & 0.091 \\
\multirow{2}{*}{ pd $^{*}$} & PYR & -1.41 & -1.49 & 0.20 & 0.655 \\
& PET & -1.67 & -2.31 & 5.72 & $\mathbf{0 . 0 1 7}$ \\
$\delta^{13} \mathrm{C}$ & PYR & -28.86 & -28.24 & 5.50 & $\mathbf{0 . 0 1 9}$ \\
& PET & -27.65 & -27.39 & 0.41 & 0.524 \\
\hline
\end{tabular}

See Table 1 for abbreviations. Units: GSF (\%), DOE (Julian day), LMA $\left(\mathrm{g} \mathrm{m}^{-2}\right), \mathrm{N}_{\mathrm{a}}\left(\mathrm{g} \mathrm{m}^{-2}\right), \Psi_{\mathrm{pd}}(\mathrm{MPa})$, and $\delta^{13} \mathrm{C}(\% \mathrm{o})$

Bold values are statistically significant $(P<0.05)$

a Median values

Direct and indirect effects of environmental conditions and seed size on leaf $\delta^{13} \mathrm{C}$

Leaf $\delta^{13} \mathrm{C}$ changed with the availability of resources; it increased with decreasing predawn water potential, in reflect of the increased WUE of plants when exposed to soil water deficit conditions (e.g. Ehleringer and Cooper 1988), and increased with increasing light. The positive effect of light on WUE was mediated by consecutive increases in LMA and nitrogen content per unit leaf area for $Q$. pyrenaica. For $Q$. petraea, however, the effect was direct (i.e. not mediated by a change on LMA) and could account for light-induced biochemical adjustments (e.g. in carboxylation capacity and electron transport rate) enhancing leaf photosynthetic capacity. From our results, it seems that nitrogen tended to favour photosynthesis over stomatal conductance for $Q$. pyrenaica (Aranda et al. 2007; Ponton et al. 2002) and that it similarly stimulated photosynthesis and stomatal conductance for $Q$. petraea (Duan et al. 2009; Meziane and Shipley 2001). Further examination of photosynthesis, stomatal conductance, and mesophyll conductance is needed to assess how consistent these differences are on the ecological requirements of the species and to what extent does $\delta^{13} \mathrm{C}$ inform on first-year WUE.

We must note that leaf $\delta^{13} \mathrm{C}$ is not solely related to photosynthetic discrimination. Leaf $\delta^{13} \mathrm{C}$ often decreases from germination/budburst as ${ }^{13} \mathrm{C}$-depleted new 
photoassimilates add to the ${ }^{13} \mathrm{C}$-enriched carbon pool mobilized from reserve organs (Damesin et al. 1998; Eglin et al. 2009; Kennedy et al. 2004; Ponton et al. 2002). This would explain why leaves of seedlings of $Q$. petraea from bigger seeds were more enriched in the isotope ${ }^{13} \mathrm{C}$ than those from smaller seeds at the end of the first year. The fact that such link was not observed for $Q$. pyrenaica suggests a different pattern of mobilization/allocation of seed carbon compounds to leaves between species (see Baraloto et al. 2005). Taking into account the higher allocation of biomass to roots in $Q$. pyrenaica and its typical sprouting habit relative to $Q$. petraea (RodríguezCalcerrada et al. 2008), seed carbohydrates could be preferentially moved from the seeds to the roots in the former species. Further, the high and rapid growth of seedlings of $Q$. petraea and its competitive ability relative to $Q$. pyrenaica would be favoured by a higher consumption of cotyledon reserves (Imaji and Seiwa 2010), which would consequently cause a higher mobilization of seed ${ }^{13} \mathrm{C}$ enriched carbohydrates to leaves and shoots.

A carry-over effect of acorn reserves on leaf $\delta^{13} \mathrm{C}$ could also explain the direct link between emergence time and leaf $\delta^{13} \mathrm{C}$. Because carbohydrates transferred from seeds are enriched in the ${ }^{13} \mathrm{C}$ isotope and new photoassimilates are depleted in ${ }^{13} \mathrm{C}$, late-emerging seedlings, with have a shorter period for photosynthesis, would have higher leaf $\delta^{13} \mathrm{C}$ (i.e. more ${ }^{13} \mathrm{C}$ ) than early-emerging seedlings at the end of the growing season. In addition, as the season advanced, leaves expanded and developed under increasingly drier air and soil water conditions, which could force some morphological and physiological adjustments that increased leaf WUE in late emerging individuals.

\section{Relevance of functional traits for survival}

The relevance of traits for survival differed between species. Q. petraea is a temperate tree only marginally present in sub-Mediterranean forests; its seedlings show an inherent tendency to grow relatively fast but are not adapted to tolerate the severe water deficits that frequently occur in these forests. As such, the probability to die was higher for the seedlings of $Q$. petraea that had experienced more severe water deficits, differently to $Q$. pyrenaica, for which levels of water deficit did not seem to exceed any threshold triggering mortality. On the other hand, leaf $\delta^{13} \mathrm{C}$ of seedlings of $Q$. pyrenaica that were alive by the second year from germination was lower than that of dying seedlings. One interpretation of the above result is that low WUE was advantageous for plants. An efficient use of water may help plants to survive persistent droughts in arid environments but be disadvantageous in seasonally dry and competitive habitats (Ehleringer 1993; Mediavilla and Escudero 2003; Nicotra and Davidson 2010; Picotte et al.
2007; Sandquist and Ehleringer 2003). Alternatively, assuming that first-year leaf $\delta^{13} \mathrm{C}$ resulted from the seed-toleaf mobilization of ${ }^{13} \mathrm{C}$-enriched components, the increasing probability of survival of $Q$. pyrenaica as leaf $\delta^{13} \mathrm{C}$ decreased could be mostly reflecting a positive effect of first-year photosynthetic carbon gain on subsequent survival. A large part of the carbon gained by photosynthesis in the first year was stored-as suggests the single flush of shoot growth-so that the more carbohydrates were stored the higher were tolerance of stress, recovery from damage and, eventually, survival in the following year (McDowell et al. 2008; Ramel et al. 2009; Seiwa 2000). The different contribution of $\delta^{13} \mathrm{C}$ to survival for each species might reside on their distinct phenology. Seedlings of $Q$. petraea emerge relatively soon, approximately 15 days earlier than those of $Q$. pyrenaica and, provided no frosts occur, can take full advantage of the most favourable period for photosynthesis: late spring; thus, variation in net carbon uptake among seedlings becomes negligible for survival. Seedlings of $Q$. pyrenaica, on the contrary, emerge almost in summer, such that drought-induced variations in net carbon uptake (e.g. due to stomata closure) can critically affect carbon reserves and become relevant for survival-with dying seedlings having more ${ }^{13} \mathrm{C}$ than surviving ones.

In conclusion, the relationship among some functional traits and the relevance of some traits for survival differ between species apparently in relation to their adaptation to drought. Vertical growth of 1-year-old seedlings seems due to a translocation of seed carbohydrates to aerial organs; growth is thus dependent on seed size and independent of the leaf carbon isotope composition, which probably reflects a balance between photosynthetic discrimination against ${ }^{13} \mathrm{C}$ (i.e. WUE) and seed-to-leaf mobilization of ${ }^{13} \mathrm{C}$ enriched compounds.

Acknowledgments We thank Guillermo González Gordaliza and Jesús Alonso for their helpful assistance in the field and Matthew T. Robson and Javier Cano for helping measuring and sowing the acorns. We are also grateful to Ruben Milla for advice on path analysis and critical reading of the manuscript, and Nicolas Fanin for constructive comments on data analysis. This work was supported by funding from projects CCG07-UPM/AMB-1865 and SUM200800004-C03-01.

Conflict of interest None.

\section{References}

Aranda I, Pardos M, Puértolas J, Jiménez MD, Pardos JA (2007) Water-use efficiency in cork oak (Quercus suber) is modified by the interaction of water and light availabilities. Tree Physiol 27:671-677 
Arbuckle JL (2003) AMOS 5 user's guide. Smallwaters Corportation, Chigago, IL

Asbjornsen H, Vogt KA, Ashton MS (2004) Synergistic responses of oak, pine and shrub seedlings to edge environments and drought in a fragmented tropical highland oak forest, Oaxaca, Mexico. For Ecol Manag 192:313-334

Augspurger CK, Cheeseman JM, Salk CF (2005) Light gains and physiological capacity of understorey woody plants during phenological avoidance of canopy shade. Funct Ecol 19:537-546

Baayen RH, Davidson DJ, Bates DM (2008) Mixed-effects modeling with crossed random effects for subjects and items. J Mem Lang 59:390-412

Baraloto C, Forget P-M, Goldberg DE (2005) Seed mass, seedling size and neotropical tree seedling establishment. J Ecol 93:1156-1166

Bates DM (2005) Fitting linear mixed models in R. R News 5:27-30

Bentler PM (1989) EQS structural equations program manual. BMDP Statistical software, Los Angeles

Bonfil C (1998) The effects of seed size, cotyledon reserves, and herbivory on seedling survival and growth in Quercus rugosa and $Q$. laurina (Fagaceaea). Am J Bot 85:79-87

Brookes PC, Wigston DL, Bourne WF (1980) The dependence of Quercus robur and Quercus petraea seedlings on cotyledon potassium, magnesium, calcium, and phosphorus during the first year of growth. Forestry 53:167-177

Casper BB, Forseth IN, Wait DA (2005) Variation in carbon isotope discrimination in relation to plant performance in a natural population of Cryptantha flava. Oecologia 145:541-548

Castro J (2006) Short delay in timing of emergence determines establishment success in Pinus sylvestris across microhabitats. Ann Bot 98:1233-1240

Castro J, Reich PB, Sánchez-Miranda A, Guerrero JD (2008) Evidence that the negative relationship between seed mass and relative growth rate is not physiological but linked to species identity: a within-family analysis of Scots pine. Tree Physiol 28:1077-1082

Cordell S, Goldstein G, Meinzer FC, Handley LL (1999) Allocation of nitrogen and carbon in leaves of Metrosideros polymorpha regulates carboxylation capacity and $\delta^{13} \mathrm{C}$ along an altitudinal gradient. Funct Ecol 13:811-818

Damesin C, Lelarge C (2003) Carbon isotope composition of currentyear shoots from Fagus sylvatica in relation to growth, respiration and use of reserves. Plant Cell Environ 26:207-219

Damesin C, Rambal S, Joffre R (1998) Seasonal and annual changes in leaf $\delta^{13} \mathrm{C}$ in two co-occurring Mediterranean oaks: relations to leaf growth and drought progression. Funct Ecol 12:778-785

Du Y, Huang Z (2008) Effects of seed mass and emergence time on seedling performance in Castanopsis chinenesis. For Ecol Manag 255:2495-2501

Duan B, Li C, Zhang X, Korpelainen H (2009) Water deficit affects mesophyll limitation of leaves more strongly in sun than in shade in two contrasting Picea asperata populations. Tree Physiol 29:1551-1561

Dudley SA (1996) Differing selection on plant physiological traits in response to environmental water availability: a test of adaptive hypotheses. Evolution 50:92-102

Eglin T, Fresneau C, Lelarge-Trouverie C, Francois C, Damesin C (2009) Leaf and twig $\delta^{13} \mathrm{C}$ during growth in relation to biochemical composition and respired $\mathrm{CO}_{2}$. Tree Physiol 29:777-788

Ehleringer JR (1993) Variation in leaf carbon isotope discrimination in Encelia farinosa: implications for growth, competition, and drought survival. Oecologia 95:340-346

Ehleringer JR, Cooper TA (1988) Correlations between carbon isotope ratio and microhabitat in desert plants. Oecologia $76: 562-566$
Farquhar GD, O'Leary MH, Berry JA (1982) On the relationship between carbon isotope discrimination and the intercellular carbon dioxide concentration in leaves. Aust J Plant Physiol 9:121-137

Farquhar GD, Ehleringer JR, Hubick KT (1989) Carbon isotope discrimination and photosynthesis. Annu Rev Plant Physiol Plant Mol Biol 40:503-537

Flexas J, Medrano H (2002) Drought-inhibition of photosynthesis in C3 plants: stomatal and non-stomatal limitations revisited. Ann Bot 89:183-189

Geber MA, Griffen LR (2003) Inheritance and natural selection on functional traits. Int J Plant Sci 164(3 Suppl):S21-S42

Gómez-Aparicio L, Pérez-Ramos IM, Mendoza I, Matías L, Quero JL, Castro J, Zamora R, Marañón T (2008) Oak seedling survival and growth along resource gradients in Mediterranean forests: implications for regeneration in current and future scenarios. Oikos 117:1683-1699

Imaji A, Seiwa K (2010) Carbon allocation to defense, storage, and growth in seedlings of two temperate broad-leaved tree species. Oecologia 162:273-281

Jones RH, Allen BP, Sharitz RR (1997) Why do early-emerging tree seedlings have survival advantages?: a test using Acer rubrum (Aceraceae). Am J Bot 84:1714-1718

Kennedy PG, Hausmann NJ, Wenk EH, Dawson TE (2004) The importance of seed reserves for seedling performance: an integrated approach using morphological, physiological, and stable isotope techniques. Oecologia 141:547-554

Khurana E, Singh JS (2004) Response of five dry tropical tree seedlings to elevated $\mathrm{CO}_{2}$ : impacts of seed size and successional status. New For 27:139-157

Long TJ, Jones RH (1996) Seedling growth strategies and seed size effects in fourteen oak species native to different soil moisture habitats. Trees 11:1-8

McDowell N, Pockman WT, Allen CD, Breshears DD, Cobb N, Kolb T, Plaut J, Sperry J, West A, Williams DG, Yepez EA (2008) Mechanisms of plant survival and mortality during drought: why do some plants survive while others succumb to drought? New Phytol 178:719-739

Mediavilla S, Escudero A (2003) Mature trees versus seedlings: differences in leaf traits and gas exchange patterns in three cooccurring Mediterranean oaks. Ann For Sci 60:455-460

Meziane D, Shipley B (2001) Direct and indirect relationships between specific leaf area, leaf nitrogen and leaf gas exchange. Effects of irradiance and nutrient supply. Ann Bot 88:915-927

Milla R, Escudero A, Iriondo JM (2009) Inherited variability in multiple traits determines fitness in populations of an annual legume from contrasting latitudinal origins. Ann Bot 103:1279-1289

Nanos N, Pardo F, Nager JA, Pardos JA, Gil L (2005) Using multivariate factorial kriging for multiscale ordination: a case study. Can J For Res 35:2860-2874

Nicotra AB, Davidson A (2010) Adaptive phenotypic plasticity and plant water use. Funct Plant Biol 37:117-127

Picotte JL, Rosenthal DM, Rhode JM, Cruzan MB (2007) Plastic responses to temporal variation in moisture availability: consequences for water use efficiency and plant performance. Oecologia 153:821-832

Ponton S, Dupouey J-L, Bréda N, Dreyer E (2002) Comparison of water-use efficiency of seedlings from two sympatric oak species: genotype $x$ environment interactions. Tree Physiol 22:413-422

Quero JL, Villar R, Marañón T, Zamora R, Poorter L (2007) Seedmass effects in four Mediterranean Quercus species (Fagaceae) growing in contrasting light environments. Am J Bot 94:1795-1803

Ramel F, Sulmon C, Gouesbet G, Couée J (2009) Natural variation reveals relationships between pre-stress carbohydrate nutritional 
status and subsequent response to xenobiotic and oxidative stress in Arabidopsis thaliana. Ann Bot 104:1323-1337

Rich PM (1990) Characterising plant canopies with hemispherical photographs. Remote Sens Rev 5:13-29

Rodríguez-Calcerrada J, Pardos JA, Gil L, Reich PB, Aranda I (2008) Light response in seedlings of a temperate (Quercus petraea) and a sub-Mediterranean species (Quercus pyrenaica): contrasting ecological strategies as potential keys to regeneration performance in mixed marginal populations. Plant Ecol 195:273-285

Rodríguez-Calcerrada J, Cano FJ, Valbuena-Carabaña M, Gil L, Aranda I (2010) Functional performance of oak seedlings naturally regenerated across microhabitats of distinct overstorey canopy closure. New For 39:245-259

Sandquist DR, Ehleringer JR (2003) Carbon isotope discrimination differences within and between contrasting populations of Encelia farinose raised under common-environment conditions. Oecologia 134:463-470

Seiwa K (1998) Advantages of early germination for growth and survival of seedlings of Acer mono under different overstorey phenologies in deciduous broad-leaved forests. J Ecol $86: 219-228$

Seiwa K (2000) Effects of seed size and emergence time on tree seedling establishment: importance of developmental constraints. Oecologia 123:208-215
Shipley B (2000) Cause and correlation in biology-a user's guide to path analysis, structural equations and causal inference. Cambridge University Press, UK

R Development Core Team (2009) R: a language and environment for statistical computing. R Foundation for statistical computing, Vienna, Austria. http://www.r-project.org

Tripathi RS, Khan ML (1990) Effects of weight and microsite characteristics on germination and seedling fitness in two species of Quercus in a subtropical wet hill forest. Oikos 57:289-296

Urbieta IR, Pérez-Ramos IM, Zavala MA, Marañón T, Kobe RK (2008) Soil water content and emergence time control seedling establishment in three co-occurring Mediterranean oak species. Can J For Res 38:2382-2393

Verdú M, Traveset A (2005) Early emergence enhances plant fitness: a phylogenetically controlled meta-analysis. Ecology 86:1385-1394

Villar-Salvador P, Heredia N, Millard P (2010) Remobilization of acorn nitrogen for seedling growth in holm oak (Quercus ilex), cultivated with contrasting nutrient availability. Tree Physiol $30: 257-263$ 